\title{
The Impact of $\alpha$-Adrenoceptors in the Regulation of the Hypotonicity-Induced Increase in Duodenal Mucosal Permeability In Vivo
}

\author{
John Sedin, David Dahlgren (1), Markus Sjöblom and Olof Nylander*
}

Department of Neuroscience, Division of Physiology, Uppsala University, 75236 Uppsala, Sweden; john.sedin@farmbio.uu.se (J.S.); david.dahlgren@farmbio.uu.se (D.D.); markus.sjoblom@neuro.uu.se (M.S.)

* Correspondence: olof.nylander@neuro.uu.se

check for

updates

Citation: Sedin, J.; Dahlgren, D.; Sjöblom, M.; Nylander, O. The Impact of $\alpha$-Adrenoceptors in the Regulation of the Hypotonicity-Induced Increase in Duodenal Mucosal Permeability In Vivo. Pharmaceutics 2021, 13, 2096 https: / / doi.org/10.3390/ pharmaceutics13122096

Academic Editors: Ken-ichi Hosoya and Marival Bermejo

Received: 15 October 2021

Accepted: 3 December 2021

Published: 6 December 2021

Publisher's Note: MDPI stays neutral with regard to jurisdictional claims in published maps and institutional affiliations.

Copyright: (c) 2021 by the authors. Licensee MDPI, Basel, Switzerland. This article is an open access article distributed under the terms and conditions of the Creative Commons Attribution (CC BY) license (https:// creativecommons.org/licenses/by/ $4.0 /)$.

\begin{abstract}
The duodenal mucosa is regularly exposed to a low osmolality, and recent experiments suggest that hypotonicity increases mucosal permeability in an osmolality-dependent manner. The aim was to examine whether the sympathetic nervous system, via action on $\alpha$-adrenoceptors, affects the hypotonicity-induced increase in duodenal mucosal permeability. The duodenum of anaesthetised rats was perfused in vivo with a $50 \mathrm{mM} \mathrm{NaCl}$ solution in the presence of adrenergic $\alpha$-adrenoceptor drugs. Studied were the effects on mucosal permeability (blood-to-lumen clearance of ${ }^{51} \mathrm{Cr}-\mathrm{EDTA}$ ), arterial blood pressure, luminal alkalinisation, transepithelial fluid flux, and motility. Hypotonicity induced a six-fold increase in mucosal permeability, a response that was reversible and repeatable. The $\alpha_{2}$-adrenoceptor agonist clonidine abolished the hypotonicity-induced increase in mucosal permeability, reduced arterial blood pressure, inhibited duodenal motility, and decreased luminal alkalinisation. The $\alpha_{2}$-adrenoceptor antagonists, yohimbine and idazoxan, prevented the inhibitory effect of clonidine on the hypotonicity-induced increase in mucosal permeability. The $\alpha_{1}$-agonist phenylephrine or the $\alpha_{1}$-antagonist prazosin elicited their predicted effect on blood pressure but did not affect the hypotonicity-induced increase in mucosal permeability. None of the $\alpha_{1}$ - or $\alpha_{2}$-adrenoceptor drugs changed the hypotonicity-induced net fluid absorption. In conclusion, stimulation of the adrenergic $\alpha_{2}$-adrenoceptor prevents the hypotonicity-induced increase in mucosal permeability, suggesting that the sympathetic nervous system has the capability to regulate duodenal mucosal permeability.
\end{abstract}

Keywords: luminal osmolality; mucosal permeability; $\alpha$-adrenoceptor agonists; $\alpha$-adrenoceptor antagonists; COX-2; clonidine; phenylephrine; yohimbine; idazoxan; prazosin

\section{Introduction}

When an individual drinks water, coffee, diet soda, or tea on an empty stomach, the duodenal mucosa will be exposed to a fluid osmolality considerably lower than in blood plasma. The low luminal osmolality induces water absorption and increases the efflux of osmolytes, which combined increase luminal osmolality. These transport processes have long been considered to occur passively across the "leaky" duodenal epithelium, by means of osmosis and solute diffusion. In 2003, Nylander and coworkers [1] demonstrated that perfusion of the duodenum with hypotonic solutions increased, in an osmolality-dependent manner, the blood-to-lumen clearance of chromium-51 labeled ethylenediamine tetraacetic acid ( ${ }^{51} \mathrm{Cr}$-EDTA), despite the presence of a marked net water absorption. Additional experiments revealed that luminal hypotonicity also increases the blood-to-lumen clearance of ${ }^{14} \mathrm{C}$-methylglucose and ${ }^{14} \mathrm{C}$-inulin, implicating increases in epithelial paracellular permeability [2]. Interestingly, the hypotonicity-induced increase in mucosal permeability showed to be fully reversible within 20 min after cessation of the hypotonic perfusion, supporting the view of a physiological response.

Further experiments in our laboratory showed that inhibition of cyclooxygenase (COX) activity, mainly the COX-2 isoform, markedly potentiated the hypotonicity-induced 
increase in mucosal permeability. This suggests that some endogenous prostanoid, presumably prostacyclin, suppresses increases in mucosal permeability [3]. Furthermore, a non-selective blockade of nicotinic acetylcholine receptors (nAChR:s) by hexamethonium abolishes the increase in mucosal permeability, implicating the involvement of a neural mechanism in the response [1]. Moreover, intravenous (iv) infusion of vasoactive intestinal peptide (VIP), a recognized neurotransmitter in the enteric nervous system, in a dose that stimulates fluid secretion and luminal alkalinisation, markedly reduced the hypotonicity-induced increase in mucosal permeability [4]. In another study, it was shown that the selective 5-hydroxytryptamine-3 $\left(5-\mathrm{HT}_{3}\right)$ receptor antagonists attenuated, and that luminally applied 5-HT augmented the hypotonicity-induced increase in duodenal mucosal permeability, suggesting that 5-HT participates in the mediation of the response [5]. Interestingly, luminally administered lidocaine, a well-known local anaesthetic and neural blocker, at a concentration that did not affect basal ${ }^{51} \mathrm{Cr}$-EDTA clearance, strongly amplified the hypotonicity-induced increase in mucosal permeability. In fact, the $100 \mathrm{mOsm}$-induced net increase in permeability in lidocaine treated rats was the same as that induced by pure water [1]. Taken together, these results strongly suggests that the hypotonicity-induced increase in duodenal mucosal permeability is physiologically regulated. It appears that there are two main mechanisms that regulate mucosal permeability; one excitatory, which is dependent on nAChR:s, and another that is inhibitory, involving some prostanoid and possibly VIP.

The autonomic nervous system participates in the regulation of intestinal function [6]. Generally speaking, the sympathetic nervous system exerts mainly inhibitory effects on gastrointestinal motility and fluid secretion. Sympathetic nerve fibers enter the intestinal wall along arteries and terminate in the myenteric and submucosal plexuses, where they control secretomotor neurons and vascular tone via $\alpha_{1}$ and $\alpha_{2}$ adrenergic signaling. In addition, adrenergic nerve fibers also travel along blood vessels into the submucosa and mucosa in close proximity to epithelial and enterochromaffin cells, where they are believed to modulate immune responses and inflammation [7].

The aim of the present study was to investigate the effects of adrenergic $\alpha$-receptors on duodenal functions, with a focus on the hypotonicity-induced increase in mucosal permeability. To accomplish this goal, the proximal duodenum of anaesthetised rats was perfused with $50 \mathrm{mM} \mathrm{NaCl}$ in the presence of $\alpha_{1}$ - and $\alpha_{2}$-adrenoceptor antagonists and agonists. The effects on blood-to-lumen clearance of ${ }^{51} \mathrm{Cr}$-EDTA, arterial blood pressure, duodenal motility, transepithelial fluid flux, and luminal alkalinization were monitored.

\section{Materials and Methods}

\subsection{Animals and Surgery}

The material in this study was in conformity with Good Publishing Practice in Physiology [8]. Male Sprague Dawley rats, purchased from Taconic, Denmark, weighing 265 to $395 \mathrm{~g}$, were housed in standard macrolon cages, Type IV (595 $\mathrm{mm} \times 380 \mathrm{~mm} \times 200 \mathrm{~mm})$, in groups of two or more animals. The rats were maintained under constant conditions (temperature $20 \pm 1{ }^{\circ} \mathrm{C}$ and $50 \pm 10 \%$ humidity) on a $12 \mathrm{~h}$ light-dark cycle. All animals had free access to food and water. Before the experiments, the animals were fasted for $16 \mathrm{~h}$ overnight, given free access to water. To minimize the preoperative stress, all rats were anesthetized with Inactin ${ }^{\circledR} 125 \mathrm{mg} \mathrm{kg}^{-1}$ intraperitoneally by experienced personal at the animal department, Biomedical Center, Uppsala University, Uppsala. The rat was then transported to the laboratory and immediately laid down on a pre-warmed heating pad. Body temperature was maintained at $37.5 \pm 0.5^{\circ} \mathrm{C}$ by a temperature regulator, connected to an intrarectal thermistor probe and a heating pad. Thereafter, the animals underwent catheterization of arteries (for assessment of mean arterial blood pressure, MABP) and veins (for infusion of ${ }^{51} \mathrm{Cr}$-EDTA and drugs), as well as abdominal surgery. The surgical procedure was the same as that described by Sedin et al. [9]. 


\subsection{Measurement of Duodenal Epithelial Permeability}

Determining the blood-to-lumen clearance of ${ }^{51} \mathrm{Cr}$-EDTA assessed duodenal epithelial permeability. The values are expressed as $\mathrm{ml}$ per min per $100 \mathrm{~g}$ wet tissue weight $\left(\mathrm{ml} \mathrm{min}{ }^{-1} 100 \mathrm{~g}^{-1}\right)$. A detailed description of this method is found elsewhere $[10,11]$.

\subsection{Measurement of Duodenal Motility}

Intraluminal pressure was used to assess duodenal motility. The inlet perfusion cannula was connected, via a T-tube, to a pressure transducer, and intraluminal pressure was recorded. The outlet was positioned at the same level as the inlet cannula. An upward deflection of at least $2 \mathrm{mmHg}$ above baseline was defined as a motor response. The changes in intraluminal pressure were recorded, via a digitizer, on a computer using Power-Lab ${ }^{\circledR}$ software (ADInstruments; Hastings, UK). Duodenal motility was assessed over intervals of $10 \mathrm{~min}$, using planimetry to measure the total area under the pressure curve (AUC) during the sample period. The values given are the mean \pm SEM of three 10 min intervals.

\subsection{Measurement of Duodenal Luminal Alkalinization}

The rate of luminal alkalinisation in the duodenum was determined by back titration of the perfusate to $\mathrm{pH} 5.0$, with $10 \mathrm{mM} \mathrm{HCl}$, under continuous gassing $\left(100 \% \mathrm{~N}_{2}\right)$, using $\mathrm{pH}$ stat equipment (Schott-Titroline Easy, Mainz, Germany). The $\mathrm{pH}$ electrode was routinely calibrated with standard buffers before titration initiation. The amount of $\mathrm{HCl}$ needed to back titrate the blank solutions to $\mathrm{pH} 5.0$ was negligible. The rate of luminal alkalinisation was expressed as micromoles of base transported per square centimetre serosal surface area per hour $\left(\mu \mathrm{mol} \mathrm{cm}{ }^{-2} \mathrm{~h}^{-1}\right)$.

\subsection{Measurement of Fluid Flux}

The duodenum continuously absorbs and secretes fluid, and the difference between these two processes determines the net flux of fluid across the epithelium. The weight of the fluid in the collection vial was used to measure the flow during the $10 \mathrm{~min}$ collection intervals. Effluent volumes were calculated by correcting for density. The absolute net fluid flux across the mucosa was determined by subtracting the effluent volume from that delivered by the peristaltic pump alone (i.e., in the absence of the intestinal segment) and expressed as $\mathrm{mL}$ of fluid per gram of wet tissue weight per hour $\left(\mathrm{mL} \mathrm{g}^{-1} \mathrm{~h}^{-1}\right)$. The rate of the peristaltic pump was determined from the mean of two samples, obtained at $10 \mathrm{~min}$ intervals, immediately after terminating each experiment. A negative flux value indicates net fluid absorption. Perfusion rate was $\sim 0.4 \mathrm{~mL} \mathrm{~min}^{-1}$.

\subsection{Experimental Protocol}

An illustration of the experimental protocol is presented in Figure 1. To prevent duodenal postoperative ileus, caused by the handling of the duodenum during the operative procedure, all animals were pre-treated with parecoxib, a selective COX-2 inhibitor. Previous experiments have shown that COX-2 inhibition restores motility, increases luminal alkalinization, and responds to luminal hypotonicity, with a larger increase in mucosal permeability and a greater rate of fluid absorption [12].

Parecoxib was administered iv, at a dose of $5 \mathrm{mg} \mathrm{kg}^{-1} 50-60 \mathrm{~min}$, prior to the start of the experiment. Subsequently, ${ }^{51} \mathrm{Cr}$-EDTA was administered as an iv bolus of $75 \mu \mathrm{Ci}$, followed by a continuously infusion, at a rate of $50 \mu \mathrm{Ci} \mathrm{h}^{-1}$. In all animals, the duodenal segment was perfused as follows: $30 \mathrm{~min}$ with isotonic saline, $30 \mathrm{~min}$ with hypotonic saline $(50 \mathrm{mM} \mathrm{NaCl}), 40 \mathrm{~min}$ recovery period with isotonic saline, $30 \mathrm{~min}$ with hypotonic saline, and, finally, a 30 min recovery period, with isotonic saline, giving a total perfusion time of $160 \mathrm{~min}$. 


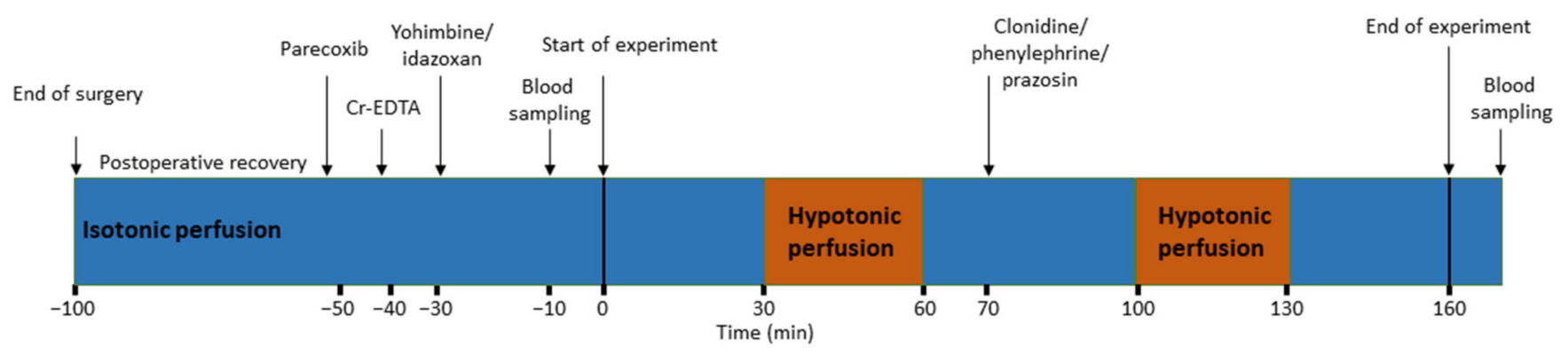

Figure 1. Schematic illustration of the drug administrations, events, and perfusion solutions (blue or red). The reader is referred to the method section for details.

The animals were divided into six groups: (1) control $(n=6)$, (2) clonidine $(n=6)$, (3) yohimbine + clonidine $(n=5)$, (4) idazoxan + clonidine $(n=5)$, (5) phenylephrine $(n=6)$, and (6) prazosin $(n=5)$. The effects on MABP, duodenal motility, luminal alkalinisation, ${ }^{51} \mathrm{Cr}$-EDTA clearance, and net fluid flux were measured.

In group 1, no drugs, besides parecoxib, were given. In group 2, and during the first $70 \mathrm{~min}$ of the experiment, the protocol was exactly the same as in group 1 . Thereafter, clonidine was administered as an iv infusion, at a dose of $10 \mu \mathrm{g} \mathrm{kg}^{-1} \mathrm{~h}^{-1}$, starting $30 \mathrm{~min}$ prior to the second hypotonic perfusion period. In group 3 , the $\alpha_{2}$-adrenoceptor antagonist yohimbine was administered as a slow iv bolus (1 min), at the dose $1.5 \mathrm{mg} \mathrm{kg}^{-1}, 30 \mathrm{~min}$ prior to start of effluent collection. Clonidine was administered as in group 2. In group 4, idazoxan, an $\alpha_{2}$-adrenoceptor antagonist was administered as an iv bolus of $100 \mu \mathrm{g} \mathrm{kg}^{-1}$, followed by an iv infusion of $200 \mu \mathrm{g} \mathrm{kg} \mathrm{g}^{-1} \mathrm{~h}^{-1} 30 \mathrm{~min}$ before the start of effluent collection. Clonidine was administered as in group 2 and 3 . The doses of yohimbine and idazoxan were taken from the literature [13-16]. In group 5, and during the first $70 \mathrm{~min}$ of the experiment, the protocol was exactly the same as in group 1 . The adrenergic $\alpha_{1}$-adrenoceptor agonist phenylephrine was given as a slow iv infusion, at the dose of $500 \mu \mathrm{g} \mathrm{kg}^{-1} \mathrm{~h}^{-1}, 30 \mathrm{~min}$ prior to the second hypotonic perfusion period. Finally, in group 6, the $\alpha_{1}$-adrenoceptor antagonist prazosin was administered as an iv bolus of $50 \mu \mathrm{g} \mathrm{kg}^{-1}$, followed by an iv infusion of $50 \mu \mathrm{g} \mathrm{kg}^{-1} \mathrm{~h}^{-1}, 30 \mathrm{~min}$ prior to the second hypotonic perfusion period. Doses of drugs were chosen from previous studies $[17,18]$.

\subsection{Chemicals}

Bovine albumin, yohimbine $\mathrm{HCl}$, phenylephrine $\mathrm{HCl}$, and idazoxan $\mathrm{HCl}$ were obtained from Sigma Chemicals (St. Louis, MO, USA). Clonidine $\mathrm{HCl}$ and prazosin $\mathrm{HCl}$ were purchased from Tocris Bioscience (Bristol, UK). ${ }^{51} \mathrm{Cr}$-EDTA was purchased from PerkinElmer Life Sciences Inc., Boston, MA, USA. Thiobutabarbital sodium salt $\left(\right.$ Inactin $^{\circledR}$ ) was obtained from RBI, Natick, MA, USA. Parecoxib (Dynastat ${ }^{\circ}$ for injection) was purchased from Pfizer Inc., New York, NY, USA.

\subsection{Statistics}

Descriptive statistics are expressed as mean \pm SEM. The statistical significance of data was tested by analysis of variance (ANOVA). Results obtained before, during, and after perfusion with hypotonic solution were compared by one-way repeated-measures ANOVA, followed by Tukey's multiple comparison test (within group), and by two-way repeated-measure ANOVA (mixed-model), followed by Bonferroni post-tests (between groups). All statistical analyses were performed on an Apple ${ }^{\circledR}$ computer, using GraphPad Prism software. A P-value less than 0.05 was considered significant.

\section{Results}

\subsection{Basal Parameters}

The median and min to max of basal values, obtained during the perfusion with isotonic saline, for group 1, 2, 5, and 6, are presented (as box plots with whiskers) in 
Figure 2a-e $(n=22-24)$. In Figure 2f, the net increase in ${ }^{51} \mathrm{Cr}$-EDTA clearance, in response to luminal hypotonicity, is shown.
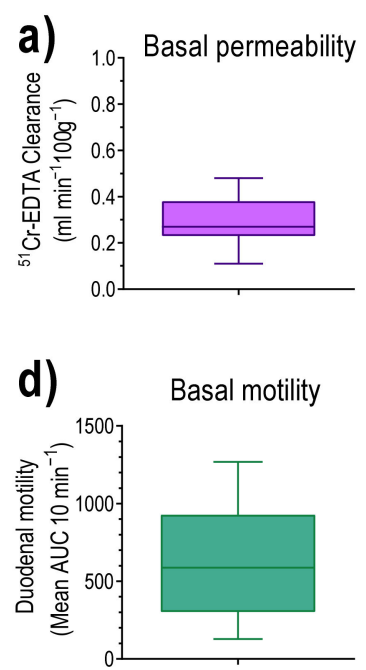

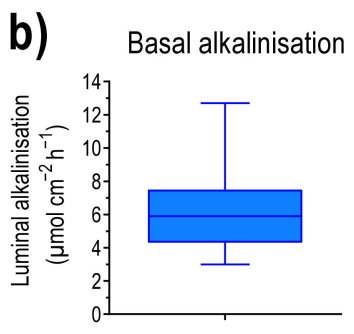

e) Basal arterial pressure

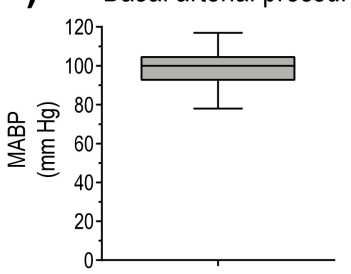

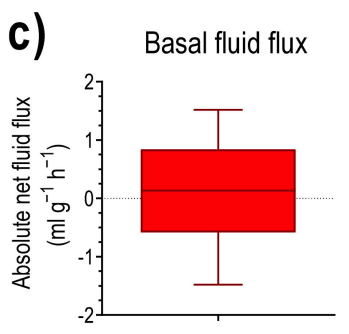

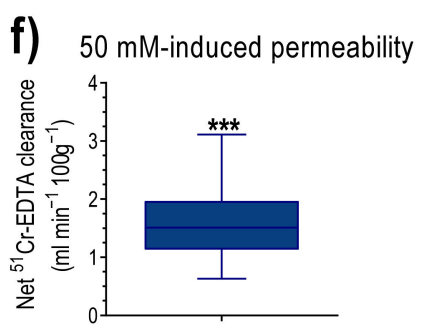

Figure 2. Basal values, in response to luminal perfusion with isotonic saline during the initial 30 min of the experiment ( $n=22-24)$. (a) Blood-to-lumen clearance of ${ }^{51}$ Cr-EDTA. (b) Duodenal luminal alkalinisation. (c) Transepithelial net fluid flux. (d) Duodenal motility. (e) Mean arterial blood pressure (MABP). (f) The net increase (the mean of the 50 and 60 min values, minus the mean of the three basal values during the perfusion with isotonic saline) in ${ }^{51}$ Cr-EDTA clearance, in response to luminal perfusion of the duodenum with $50 \mathrm{mM} \mathrm{NaCl}$. ${ }^{* *} \mathrm{P}<0.001$ compared with basal permeability (a).

\subsection{Control Rats, $M A B P,{ }^{51} C r$-EDTA Clearance, Luminal Alkalinisation, Net Fluid Absorption,} and Duodenal Motility

MABP was $106 \pm 3 \mathrm{mmHg}$ at the beginning of the experiment and decreased to $82 \pm 7 \mathrm{mmHg}(\mathrm{P}<0.05) 160 \mathrm{~min}$ later. During the initial $30 \mathrm{~min}$ perfusion with isotonic saline, the basal ${ }^{51} \mathrm{Cr}$-EDTA clearance, luminal alkalinisation, and duodenal motility were $0.35 \pm 0.02 \mathrm{~mL} \mathrm{~min}^{-1} 100 \mathrm{~g}^{-1}, 5.5 \pm 0.4 \mu \mathrm{mol} \mathrm{cm}^{-2} \mathrm{~h}^{-1}$, and $700 \pm 119$ AUC $10 \mathrm{~min}^{-1}$, respectively. The basal mean net fluid flux was $0.75 \pm 0.15 \mathrm{~mL} \mathrm{~g}^{-1} \mathrm{~h}^{-1}$ (Figure 3a). Perfusion of the duodenum with $50 \mathrm{mM} \mathrm{NaCl}$ induced net fluid absorption and increased ${ }^{51} \mathrm{Cr}$-EDTA clearance 5.5-fold $(\mathrm{P}<0.001)$, which returned to basal values within $20 \mathrm{~min}$ after cessation of the hypotonic saline perfusion (Figures $3 \mathrm{a}$ and $4 \mathrm{a}$ ). The net increase in ${ }^{51} \mathrm{Cr}-$ EDTA clearance, in response to luminal hypotonicity, was $1.58 \pm 0.23 \mathrm{~mL} \mathrm{~min}^{-1} 100 \mathrm{~g}^{-1}$. The second perfusion with $50 \mathrm{mM} \mathrm{NaCl}$, starting $40 \mathrm{~min}$ after cessation of the first one, induced an increase in ${ }^{51} \mathrm{Cr}$-EDTA $\left(1.88 \pm 0.25 \mathrm{~mL} \mathrm{~min}^{-1} 100 \mathrm{~g}^{-1}\right)$ of similar magnitude as the first one (Figure 4a). The change in net fluid flux, in response to the second hypotonic perfusion, was almost identical to the first one (Figure 3a). Luminal hypotonicity had no effect on either luminal alkalinisation or duodenal motility (Figure $4 b, c$ ).

\subsection{Effects of Clonidine ( $\alpha_{2}$-Adrenoceptor Agonist)}

During the initial $30 \mathrm{~min}$ perfusion with isotonic saline, the MABP was $94 \pm 4 \mathrm{mmHg}$, which declined to $83 \pm 5 \mathrm{mmHg}$ just prior to the infusion of clonidine. Basal ${ }^{51} \mathrm{Cr}$-EDTA clearance, luminal alkalinisation, and duodenal motility were $0.26 \pm 0.02 \mathrm{~mL} \mathrm{~min}^{-1} 100 \mathrm{~g}^{-1}$, $7.3 \pm 0.7 \mu \mathrm{mol} \mathrm{cm}^{-2} \mathrm{~h}^{-1}$, and $730 \pm 158$ AUC $10 \mathrm{~min}^{-1}$, respectively. The mean net fluid flux was $-0.12 \pm 0.12 \mathrm{~mL} \mathrm{~g}^{-1} \mathrm{~h}^{-1}$. The net increase in ${ }^{51} \mathrm{Cr}$-EDTA clearance, in response to perfusion with $50 \mathrm{mM} \mathrm{NaCl}$, was $1.88 \pm 0.25 \mathrm{~mL} \mathrm{~min}^{-1} 100 \mathrm{~g}^{-1}$, a value not different from that obtained in group 1 (Figure 4a). Clonidine infusion reduced MABP to $61 \pm 3 \mathrm{~mm} \mathrm{Hg}$ $(\mathrm{P}<0.05)$. During the perfusion with isotonic saline, in the period between the hypotonic perfusions, clonidine induced $(\mathrm{P}<0.05)$ net fluid absorption (Figure 3a). Furthermore, clonidine abolished duodenal motility $(\mathrm{P}<0.01)$ and significantly $(\mathrm{P}<0.001)$ decreased 
luminal luminal alkalinisation (Figure $4 b, c)$. Treatment with clonidine abolished $(\mathrm{P}<0.01)$ the $50 \mathrm{mM} \mathrm{NaCl}$-induced increase in ${ }^{51} \mathrm{Cr}$-EDTA clearance (Figure $4 \mathrm{a}$ ), but the change in net fluid flux was not different from that in the control group (Figure 3a).
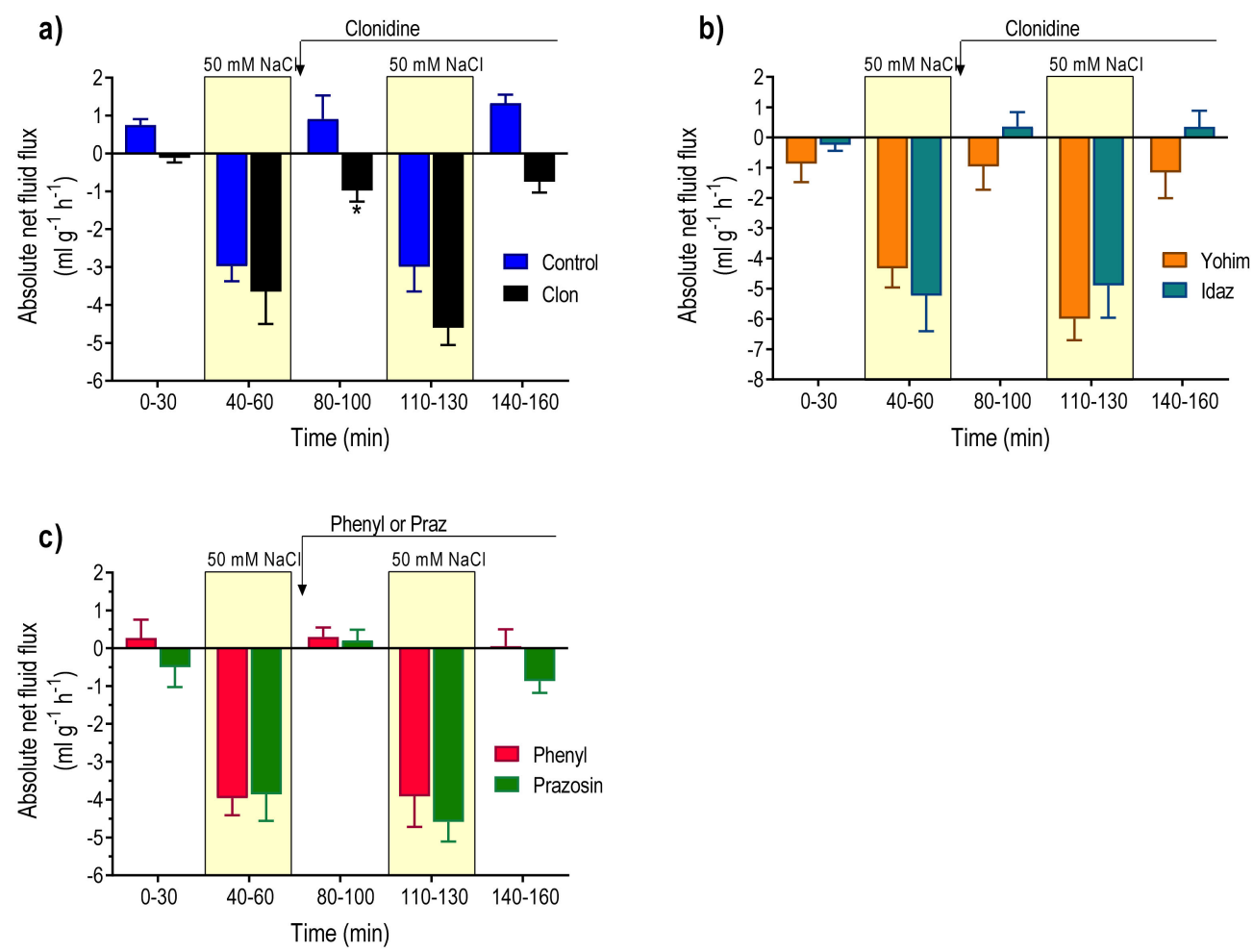

Figure 3. Effects of $\alpha$-adrenoreceptor agonists and antagonist on the absolute net fluid flux in the rat duodenum, where a minus sign indicates fluid absorption. The duodenum was perfused with isotonic saline (white area) and $50 \mathrm{mM} \mathrm{NaCl}$ hypotonic saline (yellow bar). (a) Controls $(\mathrm{n}=6)$ and effects of clonidine $(n=6)$. (b) Effects of an idazoxan $(n=5)$ or yohimbine $(n=5)$ in the absence and presence of clonidine. (c) Effects of phenylephrine $(n=6)$ or prazosin $(n=5)$. Values are mean \pm SEM. ${ }^{*} \mathrm{P}<0.05$, compared with the mean net fluid flux at time point $0-30 \mathrm{~min}$ (black bar). The reader is referred to the method section for details of the experimental setup and doses.

\subsection{Effects of Yohimbine + Clonidine ( $\alpha_{2}$-Adrenoceptor Antagonist $+\alpha_{2}$-Adrenoceptor Agonist)}

In yohimbine pre-treated animals, the MABP was $96 \pm 5 \mathrm{mmHg}$ in the beginning of the experiment and $103 \pm 4 \mathrm{mmHg} 70 \mathrm{~min}$ later, i.e., prior to the infusion of clonidine. Basal ${ }^{51} \mathrm{Cr}$-EDTA clearance $\left(0.26 \pm 0.05 \mathrm{~mL} \mathrm{~min}{ }^{-1} \mathrm{~g}^{-1}\right)$, luminal alkalinisation $\left(8.3 \pm 0.8 \mu \mathrm{mol} \mathrm{cm}{ }^{-2} \mathrm{~h}^{-1}\right)$, duodenal motility $\left(483 \pm 151\right.$ AUC $\left.10 \mathrm{~min}^{-1}\right)$, and net fluid flux $\left(-0.87 \pm 0.24 \mathrm{~mL} \mathrm{~g}^{-1} \mathrm{~h}^{-1}\right)$ were not different from the corresponding values in the controls (Figures 3 and 5). Luminal perfusion of the duodenum with $50 \mathrm{mM} \mathrm{NaCl}$ increased ${ }^{51} \mathrm{Cr}$-EDTA clearance and the net increase was $2.35 \pm 0.23 \mathrm{~mL} \mathrm{~min}^{-1} 100 \mathrm{~g}^{-1}$, significantly $(\mathrm{P}<0.05)$ higher than the corresponding value in the control group (Figure $5 \mathrm{a}$ ). Clonidine tended to reduce MABP in yohimbine-treated animals, but this effect did not attain statistical significance (data not shown). The net increase in ${ }^{51} \mathrm{Cr}$-EDTA clearance, in response to luminal hypotonicity in yohimbine, plus clonidine-treated animals $\left(1.45 \pm 0.30 \mathrm{~mL} \mathrm{~min}^{-1} 100 \mathrm{~g}^{-1}\right)$, was not different from controls but significantly higher $(\mathrm{P}<0.05)$ than in animals treated with clonidine alone (Figure 5a). Clonidine infusion attenuated $(\mathrm{P}<0.05)$, but did not abolish duodenal motility, and reduced the luminal alkalinisation in yohimbine-treated animals (Figure $5 b, c$ ). Clonidine did not affect the hypotonicity-induced net fluid flux in animals treated with yohimbine (Figure 3b). 

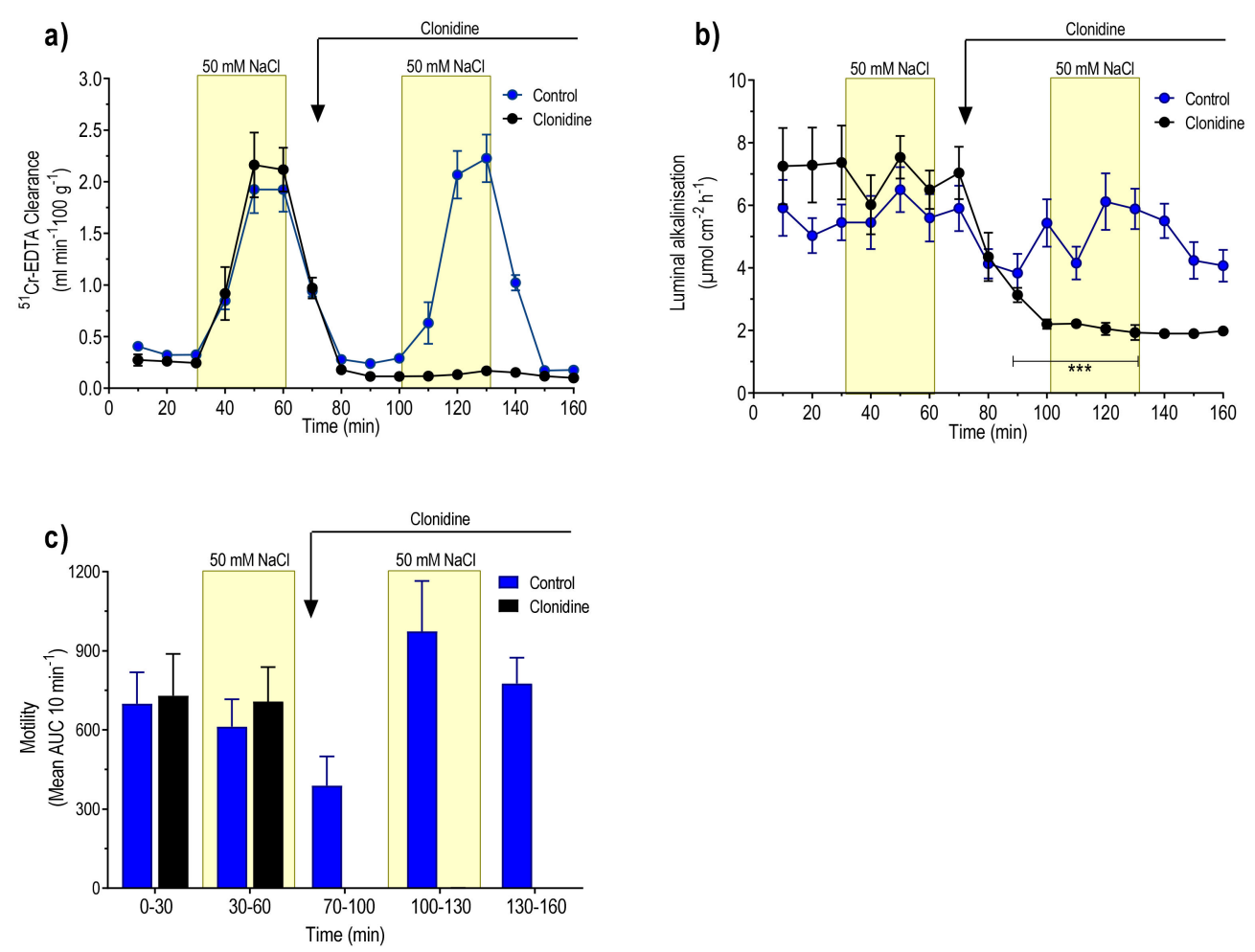

Figure 4. Effects of absence or presence of clonidine on (a) blood-to-lumen clearance of ${ }^{51} \mathrm{Cr}$-EDTA, (b) luminal alkalinization, and (c) duodenal motility. The duodenum was perfused with isotonic saline (white area) and $50 \mathrm{mM} \mathrm{NaCl}$ hypotonic saline (yellow bar). Values are mean $\pm \mathrm{SEM}, \mathrm{n}=6$ in each group. ${ }^{* *} \mathrm{P}<0.001$, compared with the 10-70 min values in the clonidine group (one-way, repeated-measure ANOVA, followed by Tukey's multiple comparison test). The reader is referred to the method section for details of the experimental setup and doses.

\subsection{Effect of Idazoxan + Clonidine ( $\alpha_{2}$-Adrenoceptor Antagonist + Aagonist)}

The MABP was $108 \pm 9 \mathrm{mmHg}$ at the beginning of the experiment and $91 \pm 10 \mathrm{mmHg}$ immediately before the administration of clonidine. Basal ${ }^{51} \mathrm{Cr}$-EDTA clearance $\left(0.38 \pm 0.05 \mathrm{~mL} \mathrm{~min}^{-1} 100 \mathrm{~g}^{-1}\right)$, luminal alkalinisation $\left(7.1 \pm 1.0 \mu \mathrm{mol} \mathrm{cm}^{-2} \mathrm{~h}^{-1}\right)$, duodenal motility, and net fluid flux $\left(-0.24 \pm 0.21 \mathrm{~mL} \mathrm{~g}^{-1} \mathrm{~h}^{-1}\right)$ were not different from the corresponding values in the control group. Luminal perfusion of the duodenum with $50 \mathrm{mM}$ $\mathrm{NaCl}$ increased ${ }^{51} \mathrm{Cr}$-EDTA clearance (Figure $5 \mathrm{a}$ ). The net increase in ${ }^{51} \mathrm{Cr}$-EDTA clearance was $1.62 \pm 0.23 \mathrm{~mL} \mathrm{~min}^{-1} 100 \mathrm{~g}^{-1}$, a value not different from the corresponding net increase in the control group. Clonidine did not affect MABP in idazoxan-treated animals (data not shown). The net increase in ${ }^{51} \mathrm{Cr}$-EDTA clearance $\left(1.98 \pm 0.35 \mathrm{~mL} \mathrm{~min}^{-1} 100 \mathrm{~g}^{-1}\right)$, in response to luminal hypotonicity in idazoxan + clonidine-treated animals, was not different from the corresponding value in the control group. In idazoxan-treated animals clonidine did not affect luminal alkalinisation and, furthermore, prevented the clonidine-induced inhibition of duodenal motility $(\mathrm{P}<0.01$ ) (Figure $5 \mathrm{~b}, \mathrm{c})$.

\subsection{Effects of Phenylephrine ( $\alpha_{1}$-Adrenoceptor Agonist)}

The MABP was $98 \pm 3 \mathrm{mmHg}$ at the beginning of the experiment and $92 \pm 2 \mathrm{mmHg}$ immediately before the start of the iv infusion of phenylephrine. Basal values, during the initial $30 \mathrm{~min}$ period of the isotonic saline perfusion, were $0.28 \pm 0.05 \mathrm{~mL} \mathrm{~min}^{-1} 100 \mathrm{~g}^{-1}$, $6.5 \pm 1.5 \mu \mathrm{mol} \mathrm{cm}{ }^{-2} \mathrm{~h}^{-1}$, and $472 \pm 85$ AUC per $10 \mathrm{~min}$ and $0.19 \pm 0.48 \mathrm{~mL} \mathrm{~g}^{-1} \mathrm{~h}^{-1}$ for ${ }^{51} \mathrm{Cr}$-EDTA clearance, luminal alkalinisation, motility, and net fluid flux, respectively. The net increase in ${ }^{51} \mathrm{Cr}$-EDTA clearance, in response to luminal perfusion with $50 \mathrm{mM} \mathrm{NaCl}$, was $1.57 \pm 0.37 \mathrm{~mL} \mathrm{~min}^{-1} 100 \mathrm{~g}^{-1}$. (Figure 6a). Intravenous infusion of phenylephrine significantly increased MABP from $92 \pm 2$ to $116 \pm 5 \mathrm{mmHg}(\mathrm{P}<0.001)$. In the presence of 
phenylephrine, luminal perfusion with $50 \mathrm{mM} \mathrm{NaCl}$ markedly increased ${ }^{51} \mathrm{Cr}$-EDTA clearance $\left(1.72 \pm 0.51 \mathrm{~mL} \mathrm{~min}^{-1} 100 \mathrm{~g}^{-1}\right)$, a value significantly larger than that in clonidinetreated animals but not different from that in controls (Figure 6a). Phenylephrine did not affect luminal alkalinisation or duodenal motility (Figure 6b,c).
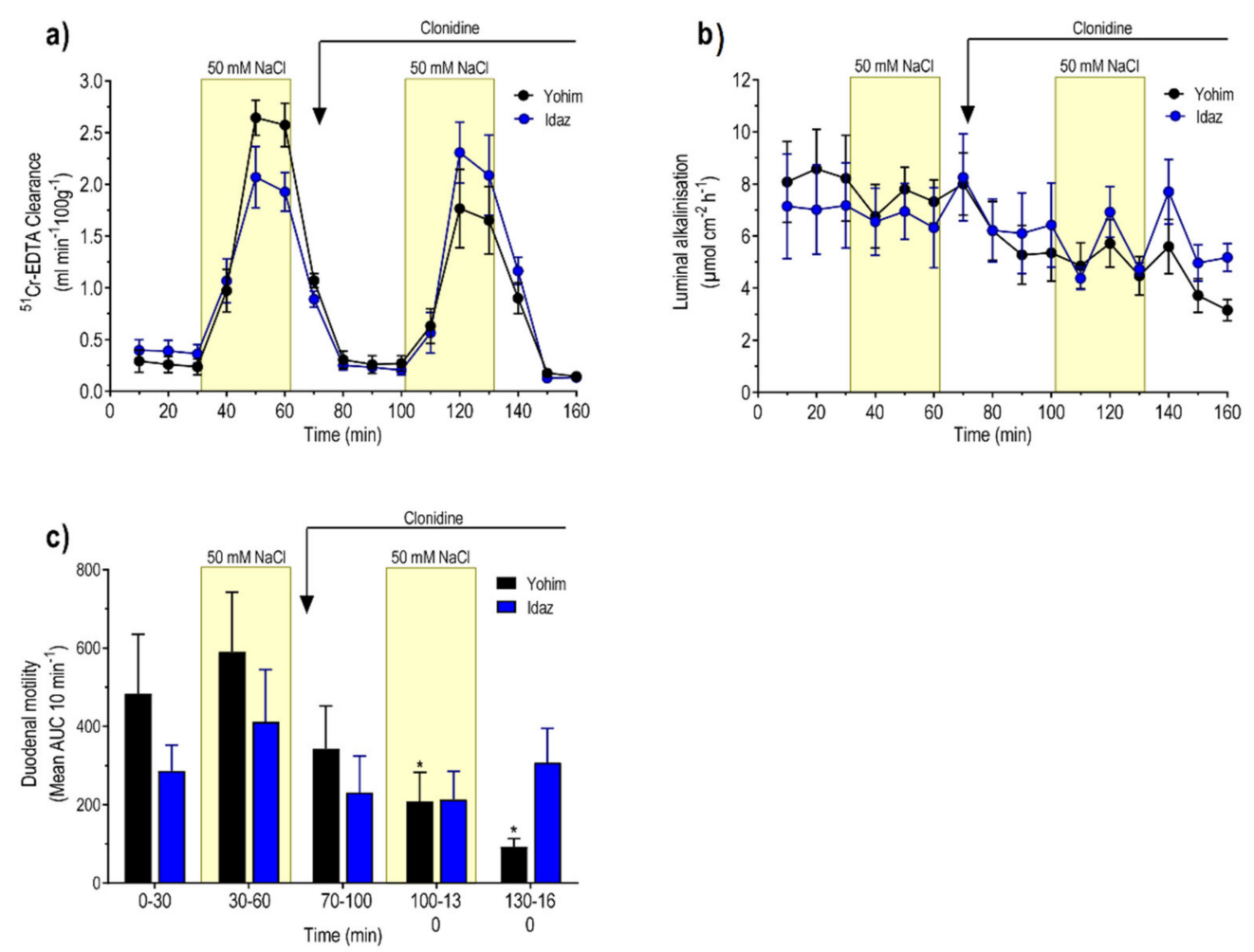

Figure 5. Effects of $\alpha 2$-adrenoreceptor antagonists (yohimbine and idazoxan), with or without clonidine, on (a) blood-to-lumen clearance of ${ }^{51} \mathrm{Cr}$-EDTA, (b) luminal alkalinisation, and (c) duodenal motility. The duodenum was perfused with isotonic saline (white area) and $50 \mathrm{mM} \mathrm{NaCl}$ hypotonic saline (yellow bar). Values are mean $\pm \mathrm{SEM}, \mathrm{n}=5$ in each group. ${ }^{*} \mathrm{P}<0.05$, compared with the values at time points $0-30$ and 30-60 min (black bar). The reader is referred to the method section for details of the experimental setup and doses.

\subsection{Effects of Prazosin ( $\alpha_{1}$-Adrenoceptor Antagonist)}

The MABP was $105 \pm 5 \mathrm{mmHg}$ at the beginning of the experiment and $98 \pm 2 \mathrm{mmHg}$ immediately before the iv injection of prazosin. Basal values, during the initial $30 \mathrm{~min}$ period of the isotonic saline perfusion, were $0.29 \pm 0.06 \mathrm{~mL} \min ^{-1} 100 \mathrm{~g}^{-1}$, $6.2 \pm 1.0 \mu \mathrm{mol} \mathrm{cm} \mathrm{cm}^{-2} \mathrm{~h}^{-1}, 517 \pm 177$ AUC per $10 \mathrm{~min}$ and $-0.49 \pm 0.53 \mathrm{~mL} \mathrm{~g}^{-1} \mathrm{~h}^{-1}$ for ${ }^{51} \mathrm{Cr}$-EDTA clearance, luminal alkalinisation, motility, and net fluid flux, respectively. The net increase in ${ }^{51} \mathrm{Cr}$-EDTA clearance, in response to luminal perfusion with $50 \mathrm{mM}$ $\mathrm{NaCl}$, was $1.31 \pm 0.18 \mathrm{~mL} \mathrm{~min}^{-1} 100 \mathrm{~g}^{-1}$, a value not different from controls (Figure 6a). Injection of prazosin decreased MABP from $98 \pm 2$ to $68 \pm 3 \mathrm{mmHg}(\mathrm{P}<0.001)$. In the presence of prazosin, luminal perfusion with $50 \mathrm{mM} \mathrm{NaCl}$ markedly increased ${ }^{51} \mathrm{Cr}$-EDTA clearance, and the net increase was $1.73 \pm 0.32 \mathrm{~mL} \mathrm{~min}^{-1} 100 \mathrm{~g}^{-1}$, a value not different from controls (Figure 6a). Prazosin did not affect luminal alkalinisation, duodenal motility, or net fluid flux (Figures $6 b, c$ and $3 c$, respectively). 

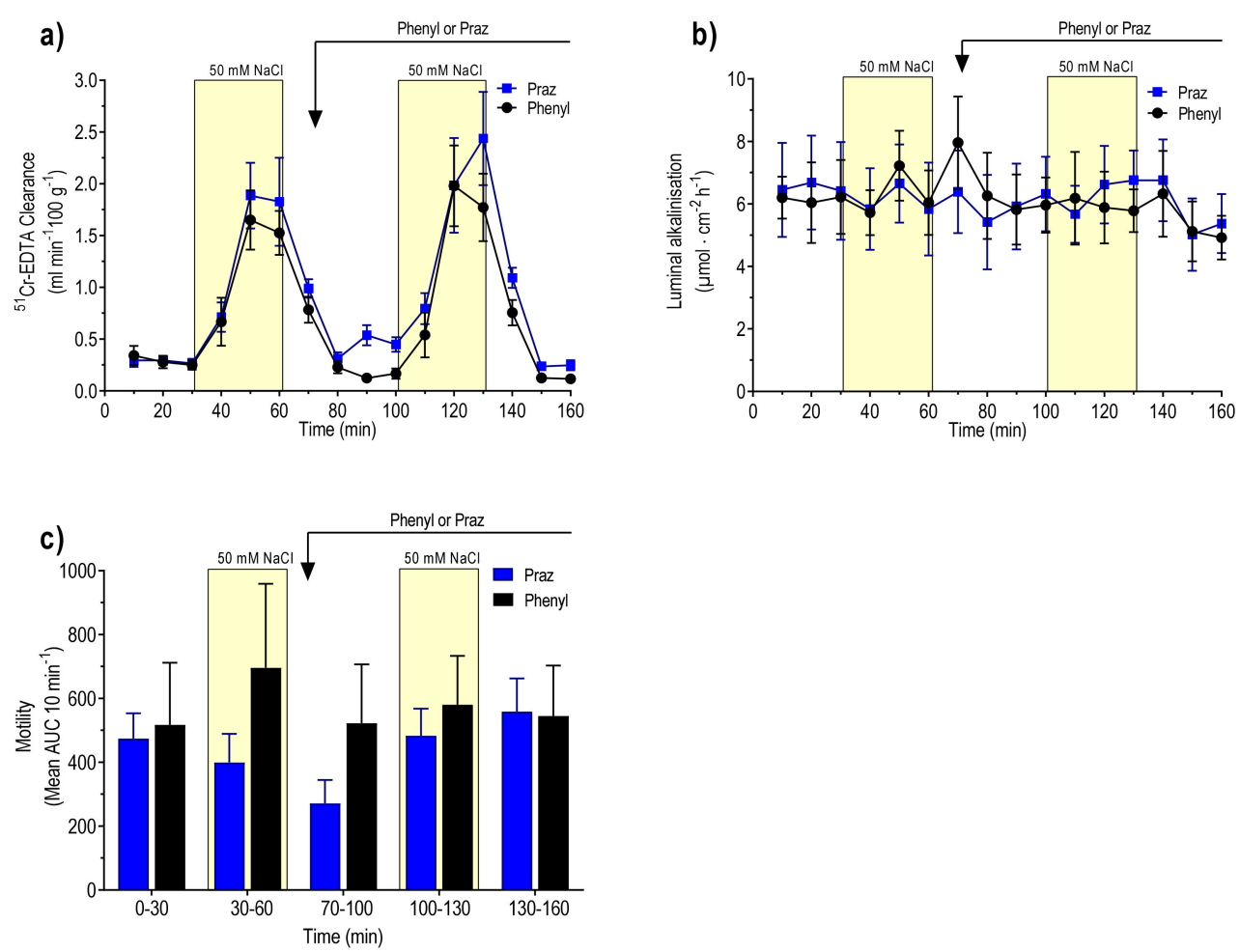

Figure 6. Effects of $\alpha_{1}$-adrenoceptor agonist (phenylephrine, $n=6$ ) and antagonist (prazosin, $n=5$ ) on (a) blood-to-lumen clearance of ${ }^{51}$ Cr-EDTA, (b) luminal alkalinization, and (c) duodenal motility. The duodenum was perfused with isotonic saline (white area) and $50 \mathrm{mM} \mathrm{NaCl}$ hypotonic saline (yellow bar). Values are mean \pm SEM. $\mathrm{P}<0.05$, compared with the values at time points $0-30$ and 30-60 min (black bar). The reader is referred to the method section for details of the experimental setup and doses.

\section{Discussion}

Previous experiments from our laboratory demonstrate that luminal hypotonic solutions increase duodenal mucosal permeability in an osmolality-dependent manner, i.e., the lower the luminal osmolality, the greater the increase in mucosal permeability. Furthermore, recent data strongly suggest that the increase in mucosal permeability is physiological regulated. The major aim of the present investigation was to elucidate whether $\alpha$-adrenergic receptor agonists and antagonists affect the hypotonicity-induced increase in duodenal mucosal permeability. For that purpose, we used the $\alpha_{2}$-adrenoceptor agonist clonidine, $\alpha_{2}$-adrenoceptor antagonists yohimbine and idazoxan, $\alpha_{1}$-adrenoceptor agonist phenylephrine, and $\alpha_{1}$-adrenoceptor antagonist prazosin. The osmolality of the perfusion solution $\left(100 \mathrm{mOsmol} \mathrm{kg}{ }^{-1} \mathrm{H}_{2} \mathrm{O}\right)$ is clearly within the physiological range, at least in humans [19]. For comparison, the effects of $\alpha$-adrenergic receptor agonists and antagonists on duodenal luminal alkalinisation, motility, transepithelial net fluid flux, and MABP were also assessed.

In this investigation, duodenal mucosal permeability was determined by measuring the flux of ${ }^{51} \mathrm{Cr}$-EDTA from blood-to-lumen. ${ }^{51} \mathrm{Cr}$-EDTA was administered iv at a constant rate throughout the experiment, and the ${ }^{51} \mathrm{Cr}$-activity assessed in the duodenal lumen and blood plasma. ${ }^{51} \mathrm{Cr}$-EDTA has to cross the capillary wall, interstitium, and epithelium before reaching the duodenal lumen. Previous data strongly suggests that the rate-limiting barrier for the blood-to-lumen movement of ${ }^{51} \mathrm{Cr}$-EDTA is the intestinal epithelium [20]. Furthermore, the hydrophilic properties [21] and cross-sectional radius of Cr-EDTA [22] suggests that the paracellular pathway constitutes the predominant route of transepithelial passage for this tracer.

Here, we confirm previous findings that luminal perfusion of the duodenum, with a $50 \mathrm{mM} \mathrm{NaCl}$ solution for $30 \mathrm{~min}$, markedly increased the blood-to-lumen clearance of ${ }^{51} \mathrm{Cr}$-EDTA, implying increases in duodenal mucosal paracellular permeability. A second 
luminal perfusion with an identical hypotonic solution, starting 40 min after cessation of the first one, induced virtually, the same increase in mucosal permeability as the first one, demonstrating excellent reproducibility. Moreover, in both instances, the recovery of mucosal permeability after the cessation of the hypotonic perfusion was fast, within $20 \mathrm{~min}$, significative of a physiological response.

Intravenous infusion of clonidine abolished the hypotonicity-induced increase in duodenal mucosal permeability. This effect of clonidine was prevented by $\alpha_{2}$-adrenoceptor antagonist, yohimbine, and idazoxan, suggesting that clonidine abolishes the hypotonicityinduced increase in mucosal permeability via stimulation of $\alpha_{2}$-adrenoceptors. Interestingly, iv administration of the $\alpha_{1}$-adrenoceptor agonist phenylephrine or the $\alpha_{1}$-adrenoceptor antagonist prazosin exerted their predicted effect on arterial blood pressure but had virtually no effect on any of the duodenal functions studied. Hence, these data raise the possibility that increased activity in sympathetic nerves to the duodenum, via an action of noradrenalin on $\alpha_{2}$-adrenoceptors, have the capability of reducing the hypotonicityinduced increase in mucosal permeability.

So, what is the mechanism by which clonidine inhibits the hypotonicity-induced increase in mucosal permeability? In a study by Ahsan et al. [23], in isolated rabbit ileum, it was suggested that $\alpha_{2}$-agonists reduce interstitial fluid pressure by depressing smooth muscle tone. A decrease in interstitial fluid pressure may reduce the driving forces for the transport of ${ }^{51} \mathrm{Cr}$-EDTA from interstitium-to-lumen. Previous data, and those in the present study, indicate that the magnitude of the hypotonicity-induced increase in mucosal permeability may be coupled to duodenal smooth muscle activity. Indeed, experiments in rat duodenum have shown that COX-inhibition, which induces duodenal motility, results in a greater increase in the hypotonicity-induced increase in mucosal permeability, compared to control animals lacking contraction [1]. Administration of iloprost, a prostacyclin analogue, reversed the response of COX inhibition on both motility and the hypotonicity-induced increase in mucosal permeability, suggesting that prostacyclin is responsible. Moreover, in the same study, it was shown that blockade of nicotinic receptors by hexamethonium markedly reduced duodenal motility and, at the same time, abolished the hypotonicityinduced increase in mucosal permeability. In the present study, it was shown that the $\alpha$-adrenoceptors antagonists idazoxan and prazosin, or the agonist phenylephrine, neither effected the parecoxib-induced duodenal motility nor the hypotonicity-induced increase in mucosal permeability. In contrast, clonidine abolished duodenal motility and markedly reduced the hypotonicity-induced increase in mucosal permeability. Although these results support a close coupling between increased duodenal smooth muscle activity and hypotonicity-induced increase in mucosal permeability, it should be noted that increased duodenal motility does not increase basal mucosal permeability per se [24]. Moreover, it has previously been shown that iv infusion of VIP, a neuropeptide released from enteric neurons, markedly reduces, similar to clonidine, the hypotonicity-induced increase in mucosal permeability but without affecting duodenal motility [4]. Furthermore, it has been shown that the nicotinic receptor antagonist hexamethonium abolished duodenal motility but did not affect the ethanol-induced increase in duodenal mucosal permeability [25]. It, therefore, seems unlikely that attenuation of duodenal smooth muscle tone by clonidine is the major causative factor inhibiting the hypotonicity-induced increase in mucosal permeability.

The inhibitory effect of clonidine on duodenal motility is in agreement with previous findings in conscious rats [24]. It is generally believed that clonidine reduces arterial blood pressure by a central mechanism, at least in part, via inhibition of sympathetic tone to the vasculature, thereby reducing peripheral resistance $[14,26]$. The inhibitory effect of clonidine on duodenal motility occurred within minutes after onset of the iv infusion, well before any effect on MABP was seen, suggesting a peripheral effect of clonidine, as well. Since small intestinal motility is regulated by neural mechanisms, it seems likely that clonidine exerts its inhibitory action on duodenal motility via depression of excitatory motor neurons in the enteric nervous system. The prevailing view is that 
this occurs via activation of inhibitory $\alpha_{2}$-adrenoceptors on cholinergic nerve terminals in muscularis externa [6].

Another possibility is that clonidine attenuates the hypotonicity-induced increase in mucosal permeability by reducing duodenal mucosal blood flow via an $\alpha$-adrenoceptorinduced arteriole vasoconstriction. Arteriole vasoconstriction may impede fluid filtration across the capillary wall, thereby reducing interstitial fluid pressure, which, in turn, reduces paracellular fluid transport. However, here we show that the $\alpha_{1}$-adrenoceptor agonist phenylephrine, a potent vasoconstrictor, did not affect the hypotonicity-induced increase in mucosal permeability. Furthermore, previous experiments in rat duodenum have shown that phenylephrine increases vascular resistance and reduces blood flow by about $20 \%$ [25] Interestingly, the $\alpha_{1}$-adrenoceptor antagonist prazosin decreased the mean arterial blood pressure, as did clonidine, without affecting the hypotonicity-induced increase in duodenal mucosal permeability. Additionally, prazosin have been shown to decrease both vascular resistance and blood flow in rat duodenum [25]. Hence, it seems highly unlikely that the hypotonicity-induced increase in mucosal permeability is related to changes in vascular resistance or blood flow.

Based on these data, we, therefore, need to look for another mechanism of action of clonidine in inhibiting the hypotonicity-induced increase in mucosal permeability. As expected, luminal hypotonicity markedly increases the absorption of water. It seems reasonable to assume that water absorption causes the enterocytes in the villous enterocytes to swell, which may be sensed by intrinsic primary neurons beneath the epithelium. This, in turn, could elicit an intramural reflex, involving the activation of a population of enteric neurons innervating the crypts, resulting in increased paracellular solute permeability (Figure 7).

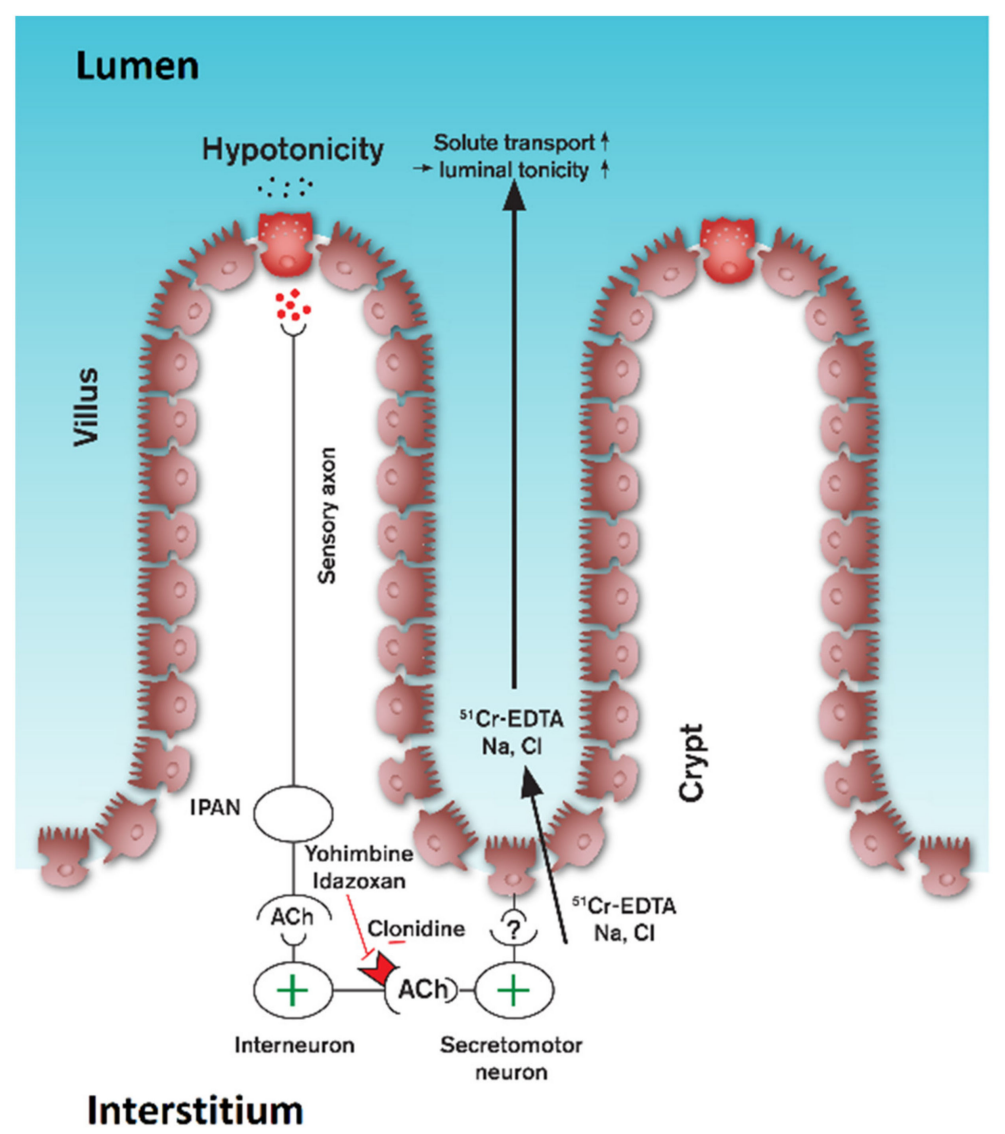

Figure 7. Our proposal for the mechanism by which clonidine inhibits the hypotonicity-induced increase in mucosal permeability via stimulation of the $\alpha_{2}$-adrenoceptor (autoreceptor). This, in turn, leads to inhibition of the hypotonicity-induced stimulation of secretomotor neurons. 
The view of activation of an intramural reflex is indirectly supported by the finding in rat duodenum that $50 \mathrm{mM} \mathrm{NaCl}$ increases the release of 5-HT, presumably from enterochromaffin cells, and that $5-\mathrm{HT}_{3}$-receptor antagonists attenuate the hypotonicity-induced increase in mucosal permeability. Furthermore, the ganglionic blocker hexamethonium, as well as VIP, abolishes the hypotonicity-induced increase in duodenal mucosal permeability. The physiological function of dilation of the paracellular pathways may be to increase the interstitium-to-lumen diffusion of solutes, such as sodium, which thereby facilitates the adjustment of luminal osmolality [1,4]. Clonidine, acting on $\alpha_{2}$-adrenoceptors on cholinergic nerve terminals or, less likely, via direct effect on epithelial cells [27-29], may inhibit the intracellular signal transmission that mediates the increase in tight junction permeability. Activation of epithelial myosin-light chain kinase has been proposed as a critical regulator of increased tight junction permeability [30], and it would, therefore, be of great interest to test whether their activity is affected by luminal hypotonicity and clonidine.

\section{Conclusions}

Luminal hypotonicity markedly and reversibly increases duodenal mucosal permeability, an effect possibly aimed to increase the blood-to-lumen transport of $\mathrm{Na}^{+}$, which contributes to an increased luminal osmolality. We demonstrated that stimulation of adrenergic $\alpha_{2^{-}}$, but not $\alpha_{1}$-receptors, abolishes the hypotonicity-induced increase in mucosal permeability. As the sympathetic nervous system modulates a variety of gastrointestinal functions, it seems likely that it also participates in the regulation of duodenal mucosal permeability. The physiological function of this effect is not known, but it is possible that in life-threatening situations or in response to acute stress, when the body needs to maintain an adequate extracellular fluid and blood volume, the central nervous system, via activation of the sympathetic nervous system, down-regulates some functions in the gastrointestinal tract. The purpose may be to reduce energy expenditures in the gut, for instance, by inhibiting motility and electrolyte fluid secretion, as well as tightening of the epithelial barrier.

Author Contributions: Conceptualization, J.S., D.D., M.S. and O.N.; methodology, J.S., D.D., M.S. and O.N.; software, J.S., D.D., M.S. and O.N.; validation, J.S., D.D., M.S. and O.N.; formal analysis, J.S., D.D., M.S. and O.N.; investigation, J.S., D.D., M.S. and O.N.; resources, J.S., D.D., M.S. and O.N.; data curation, J.S., D.D., M.S. and O.N.; writing-original draft preparation, J.S., D.D., M.S. and O.N.; writing - review and editing, J.S., D.D., M.S. and O.N.; visualization, J.S., D.D., M.S. and O.N.; supervision, J.S., D.D., M.S. and O.N.; project administration, J.S., D.D., M.S. and O.N.; funding acquisition, J.S., D.D., M.S. and O.N. All authors have read and agreed to the published version of the manuscript.

Funding: This research received no external funding.

Institutional Review Board Statement: The study was and approved by the local ethics committee for animal research (no: C250/12) in Uppsala, Sweden.

Data Availability Statement: The data presented in this study are available on request from the corresponding author.

Conflicts of Interest: The authors declare no conflict of interest.

\section{References}

1. Nylander, O.; Pihl, L.; Perry, M. Hypotonicity-induced increases in duodenal mucosal permeability facilitates adjustment of luminal osmolality. Am. J. Physiol.-Gastrointest. Liver Physiol. 2003, 285, G360-G370. [CrossRef] [PubMed]

2. Pihl, L.; Wilander, E.; Nylander, O. Comparative study of the effect of luminal hypotonicity on mucosal permeability in rat upper gastrointestinal tract. Acta Physiol. 2008, 193, 67-78. [CrossRef] [PubMed]

3. Pihl, L.; Nylander, O. Products of cyclooxygenase-2 depress duodenal function in rats subjected to abdominal surgery. Acta Physiol. 2006, 186, 279-290. [CrossRef] [PubMed]

4. Nylander, O.; Sjöblom, M. Modulation of mucosal permeability by vasoactive intestinal peptide or lidocaine affects the adjustment of luminal hypotonicity in rat duodenum. Acta Physiol. 2007, 189, 325-335. [CrossRef] [PubMed] 
5. Nylander, O.; Pihl, L. Luminal hypotonicity increases duodenal mucosal permeability by a mechanism involving 5hydroxytryptamine. Acta Physiol. 2006, 186, 45-58. [CrossRef] [PubMed]

6. Lomax, A.; Sharkey, K.; Furness, J. The participation of the sympathetic innervation of the gastrointestinal tract in disease states. Neurogastroenterol. Motil. 2010, 22, 7-18. [CrossRef] [PubMed]

7. Brinkman, D.J.; Ten Hove, A.S.; Vervoordeldonk, M.J.; Luyer, M.D.; de Jonge, W.J. Neuroimmune interactions in the gut and their significance for intestinal immunity. Cells 2019, 8, 670. [CrossRef] [PubMed]

8. Persson, P.; Henriksson, J. Good Publication Practise in Physiology; Wiley-Blackwell Commerce Place: Malden, MA, USA, 2011.

9. Sedin, J.; Sjöblom, M.; Nylander, O. The selective cyclooxygenase-2 inhibitor parecoxib markedly improves the ability of the duodenum to regulate luminal hypertonicity in anaesthetized rats. Acta Physiol. 2012, 205, 433-451. [CrossRef] [PubMed]

10. Nylander, O.; Kvietys, P.; Granger, D.N. Effects of hydrochloric acid on duodenal and jejunal mucosal permeability in the rat. Am. J. Physiol.-Gastrointest. Liver Physiol. 1989, 257, G653-G660. [CrossRef] [PubMed]

11. Nylander, O.; Hällgren, A. Duodenal mucosal permeability: Relevance to ulcerogenesis. Pathophysiology 1998, 5, 155-166. [CrossRef]

12. Nylander, $\mathrm{O}$. The impact of cyclooxygenase inhibition on duodenal motility and mucosal alkaline secretion in anaesthetized rats. Acta Physiol. 2011, 201, 179-192. [CrossRef]

13. Hubbard, J.W.; Pfister, S.L.; Biediger, A.M.; Herzig, T.C.; Keeton, T.K. The pharmacokinetic properties of yohimbine in the conscious rat. Naunyn-Schmiedebergs Arch. Pharmacol. 1988, 337, 583-587. [CrossRef]

14. Vayssettes-Courchay, C.; Bouysset, F.; Cordi, A.A.; Laubie, M.; Verbeuren, T.J. A comparative study of the reversal by different alpha 2-adrenoceptor antagonists of the central sympatho-inhibitory effect of clonidine. Br. J. Pharmacol. 1996, 117, 587-593. [CrossRef]

15. Jonson, C.; Fandriks, L. Splanchnic nerve stimulation inhibits duodenal HCO3- secretion in the rat. Am. J. Physiol. 1988, 255, G709-G712. [CrossRef]

16. Valles, J.; Prunonosa, J.; Menargues, A.; Nomen, M.; Obach, R. Oral idazoxan bioavailability in rat. Relevance of intestinal and hepatic first-pass effect. Drug Metab. Dispos. 1989, 17, 673-676.

17. Nylander, O.; Hallgren, A.; Holm, L. Duodenal mucosal alkaline secretion, permeability, and blood flow. Am. J. Physiol.Gastrointest. Liver Physiol. 1993, 265, G1029-G1038. [CrossRef]

18. Nylander, O.; Flemström, G. Effects of alpha-adrenoceptor agonists and antagonists on duodenal surface epithelial HCO3secretion in the rat in vivo. Acta Physiol. Scand. 1986, 126, 433-441. [CrossRef]

19. Gisolfi, C.; Summers, R.; Lambert, G.; Xia, T. Effect of beverage osmolality on intestinal fluid absorption during exercise. J. Appl. Physiol. 1998, 85, 1941-1948. [CrossRef]

20. Crissinger, K.; Kvietys, P.; Granger, D. Pathophysiology of gastrointestinal mucosal permeability. J. Intern. Med. 1990, 228 , 145-154. [CrossRef]

21. Bjarnason, I.; Macpherson, A.; Hollander, D. Intestinal permeability: An overview. Gastroenterology 1995, 108, 1566-1581 [CrossRef]

22. Jenkins, R.; Bell, R. Molecular radii of probes used in studies of intestinal permeability. Gut 1987, 28, 110. [CrossRef] [PubMed]

23. Ahsan, M.; Naftalin, R.; Smith, P. A submucosal mechanism for catecholamine-induced increases in fluid absorption in rabbit ileum in vitro. J. Physiol. 1988, 404, 385-405. [CrossRef] [PubMed]

24. Thollander, M.; Hellström, P.; Svensson, T. Suppression of small intestinal motility and morphine withdrawal diarrhoea by clonidine: Peripheral site of action. Acta Physiol. Scand. 1989, 137, 385-392. [CrossRef] [PubMed]

25. Sommansson, A.; Saudi, W.S.W.; Nylander, O.; Sjöblom, M. Melatonin inhibits alcohol-induced increases in duodenal mucosal permeability in rats in vivo. Am. J. Physiol.-Gastrointest. Liver Physiol. 2013, 305, G95-G105. [CrossRef] [PubMed]

26. Szabo, B. Imidazoline antihypertensive drugs: A critical review on their mechanism of action. Pharmacol. Ther. 2002, 93, 1-35. [CrossRef]

27. Chang, E.B.; Field, M.; Miller, R.J. Enterocyte alpha 2-adrenergic receptors: Yohimbine and p-aminoclonidine binding relative to ion transport. Am. J. Physiol.-Gastrointest. Liver Physiol. 1983, 244, G76-G82. [CrossRef]

28. Paris, H.; Voisin, T.; Remaury, A.; Rouyer-Fessard, C.; Daviaud, D.; Langin, D.; Laburthe, M. Alpha-2 adrenoceptor in rat jejunum epithelial cells: Characterization with $[3 \mathrm{H}] \mathrm{RX} 821002$ and distribution along the villus-crypt axis. J. Pharmacol. Exp. Ther. 1990, 254, 888-893.

29. Valet, P.; Senard, J.-M.; Devedjian, J.-C.; Planat, V.; Salomon, R.; Voisin, T.; Drean, G.; Couvineau, A.; Daviaud, D.; Denis, C. Characterization and distribution of alpha 2-adrenergic receptors in the human intestinal mucosa. J. Clin. Investig. 1993, 91, 2049-2057. [CrossRef]

30. Zuo, L.; Kuo, W.-T.; Turner, J.R. Tight junctions as targets and effectors of mucosal immune homeostasis. Cell. Mol. Gastroenterol. Hepatol. 2020, 10, 327-340. [CrossRef] 